\title{
Organizar redes sociales como instrumentos de educación, conocimiento y comunicación entre las naciones. Asuntos pendientes y nuevas reflexiones
}

\author{
Dr. Juan de Dios González Ibarra \\ Rector del Colegio de Morelos (México) \\ Secretario General de la Academia \\ Hispanoamericana de la Complejidad \\ drdiosgi@hotmail.com
}

Recepción:13/05/2021 Aceptación: 13/06/2021

\section{Resumen}

En general las redes sociales con todas sus variables y manifestaciones constituyen monopolios con poder a nivel global, que ameritan regulación por medio de la Organización de las Naciones Unidas (ONU) y, en lo particular, es indispensable combatir el anonimato en la emisión indiscriminada de noticias falsas (fake news) que afectan reputaciones, prestigios, honras y vidas humanas, así como a gobiernos, instituciones, organizaciones y empresas a nivel mundial. Se reflexiona acerca de la influencia del internet en la sociedad, la importancia de la educación en un mundo globalizado, se aportan propuestas para incidir en ello y, se destaca la perspectiva de los países como grandes organizaciones que pueden superarse por medio de la educación.

\section{Palabras clave}

Educación, redes sociales, normatividad, anonimato, noticias falsas.

\begin{abstract}
Generally speaking, in all their variables and manifestations constitute monopolies with global power. Therefore, a regulation by the United Nations (UN) is necessary. In particular, it is essential to fight anonymity in the indiscriminate broadcasting of fake news affecting reputations, prestige, honor and human lives, as well as governments, institutions, organizations and companies worldwide. This article reflects on the social influence of the Internet and on the importance of education in a globalized world. Furthermore, it offers proposals to influence it, as well as a vision of the countries seen as large organizations that can progress through education.
\end{abstract}

\section{Keywords}

Education, social networks, regulations, anonymity, fake news. 


\section{Síntesis y aportaciones}

Este artículo toma como punto de partida el reconocimiento de las redes sociales como parte importante de la sociedad actual, sin embargo, hay que promover su integración para fines positivos, regulándolas e incorporándolas a una dinámica educativa propia de los países que operan como organizaciones inteligentes.

El enfoque del tema se realiza a través de una exposición de perspectiva transdisciplinaria acerca de las teorías de la comunicación y de la información con el objeto de presentar una mejor aproximación a nuestros problemas. Para ello, nos apoyaremos en el pensamiento de diversos autores y escuelas para aportar nuestras conclusiones y propuestas respecto al tema.

A lo largo del trabajo se hace alusión a diversos problemas como la falta de regulación de las redes sociales, el camino que han seguido algunos países a nivel educativo para avanzar en esta integración, y se reflexiona sobre su experiencia para avanzar en la propuesta de algunas soluciones como parte de los estudios comparativos.

Las implicaciones prácticas de lo que se propone, abonarían a un mayor control de las redes sociales como organismos inteligentes y ayudarían al avance educativo que necesitan las naciones. Las implicaciones sociales son positivas y benefician a la sociedad a todos los niveles: educativo y organizacional.

La originalidad de este trabajo consiste en incorporar los avances y conocimientos de la última tecnología de las redes sociales en el ámbito de la educación y el progreso de las naciones vistas como organizaciones inteligentes. Todo esto a través de una metodología de la complejidad y la transdisciplina propia de las Ciencias Sociales y las Humanidades.

\section{Las redes sociales}

Comenzaremos el presente texto exponiendo que Aristóteles es considerado por muchos el primer filósofo que reflexionó acerca de la comunicación humana y afirmó que está por encima de otras disciplinas, por ejemplo, "La retórica es correlativa de la dialéctica, pues ambas versan sobre cosas que, de alguna manera, son conocidas por todos y no las delimita o incluye ninguna ciencia, ellas intentan inquirir y resistir a una razón, defenderse y acusar. Y de ellos, unos lo hacen al azar, otros, mediante el hábito que nace del ejercicio" (Aristóteles, 2007, p. 83).

Klaus Bruhn confirma lo anterior al afirmar que "En el siglo IV a. C., Aristóteles expuso lo que probablemente sea el primer modelo de la comunicación: 'las experiencias mentales de los sonidos que los hombres hablan son iguales para todos', como también lo son aquellas cosas, cuyas imágenes representan nuestras experiencias", por ello, también considera que "Las cosas del mundo, sus representaciones mentales y las expresiones orales y escritas de la gente respecto de las cosas, así como sus representaciones, son los elementos mínimos necesarios de la mayoría de las teorías del conocimiento y la comunicación" (Bruhn, 2014, p. 46). De este modo, Aristóteles establece como elementos importantísimos de la comunicación a las representaciones mentales y las imágenes para dar a conocer las experiencias personales.

Comencemos por señalar que el concepto de comunicación no es unívoco ni mucho menos lineal, sino que "Es problemático y complejo, abarca fenómenos comunes en contextos muy diversos: físicos, biológicos, sociales, cambiantes incluso en un mismo contexto, una conversación entre dos interlocutores, una reacción a una señal de tráfico son dos hechos comunicativos sociales y, no obstante, sustancialmente diferentes". Por lo anterior se comparten en él diversas dimensiones y niveles de significado, puesto que "Es amplio y elástico, que se desliza constantemente entre la polisemia, la ambigüedad y la multidimensionalidad" (Aguado, 2004, p. 10). Así, en un acto de comunicación aparentemente sencillo, influyen múltiples factores, todos ellos llenos de sentido.

En cuanto al desarrollo del conocimiento se considera que en distintas épocas a lo largo de la historia de la humanidad y "Hasta la fecha se han dado tres grandes revoluciones científicas: la primera corresponde al ascenso triunfal de la burguesía, va desde Roger Bacon hasta Francis Bacon hacia el año de 1900. Es toda la ciencia clásica que se encarna en grandes figuras como Galileo, Newton, Descartes, Pasteur, Vesalius, Leeuwenhoek, Dalton y Maxwell, entre otros muchos, ésta es manifiestamente mecánica o mecanicista y determinista" (Maldonado, 2020, p. 18).

La segunda comenzó en 1900 con Max Planck y su afirmación de los cuantos, pero con Albert Einstein en 1905 se desarrolló aún más con sus múltiples artículos sobre física, mecánica y teoría cuántica que abarca hasta su aplicación en las Ciencias Sociales que hoy estamos viviendo, traslapada con la tercera que es la de la información y la comunicación con las nuevas computadoras cuánticas -ante el agotamiento de la tecnología del silicón conforme la Ley de Moore- de las que, según información del periódico El País el 03 de abril de 2021, el psicólogo y doctor en computación por la Universidad 
Politécnica de Madrid, Mario Plattini Velthuis manifestó el grado de avance tecnológico dado en el campo de conocimiento con la "Computación cuántica: un salto tan grande como el que hubo entre el ábaco y la informática actual. Los próximos computadores solucionarán en segundos problemas que las máquinas actuales más potentes tardarían miles de años en resolver".

Para el doctor en economía de la Universidad de Harvard y creador del Foro Económico Mundial (fEM) ${ }^{1}$ Klaus Schwab, nos encontramos en una era claramente distinta a las anteriores: "Hoy estamos en los albores de la cuarta revolución industrial. Esta comenzó a principios de este siglo y se basa en la revolución digital" (Schwab, 2017, p. 20) y explica aquellos elementos que la constituyen y evidencian un adelanto tecnológico impresionante que hace unas décadas hubiera sido propio de la ciencia ficción, ya que ésta etapa "Se caracteriza por un internet más ubicuo y móvil, por sensores más pequeños y potentes que son cada vez más baratos, y por la inteligencia artificial y el aprendizaje de la máquina".

Para otros autores como el colombiano Carlos Eduardo Maldonado, es indispensable unir la razón con el sentimiento: "El encuentro, entre el diálogo y la unión, entre arte y ciencia" (Maldonado, 2021, p. 34). Tomando en cuenta las distintas eras, cuyo elemento característico fue, por ejemplo, en el siglo XIx la era de la máquina, en el siglo xx la de la información y en el siglo XXI será la era cuántica.

Hoy, la empresa IBM ya tiene un procesador cuántico, por ello, hay que señalar que en la información cuántica el concepto base es el cúbit que va de los valores del cero al uno, lo que en términos prácticos y teóricos implica el infinito, y desde luego-como es lógico- hay problemas pendientes de resolver, pero el camino ya está o fue trazado por Einstein desde 1905 en sus famosos artículos enviados a la revista más prestigiosa de ese momento Anales de Física (Annalen der Physiik), cuya información era de tal relevancia que cualquiera de ellos bien valía un Premio Nobel. Aquellos temas sintetizados de manera muy sucinta fueron los siguientes:

1) El efecto fotoeléctrico, publicado en junio de 1905, gracias al que ganó el Premio Nobel de Física en 1921, en el cual señaló que la luz está conformada por ondas y partículas (cuantos de la luz). Con ello, cambió la física para siempre.

2) Su postulado sobre las dimensiones moleculares, con el que se doctoró en la Universidad de Zúrich, en

1 El fEM es una organización sin fines de lucro que pretende la armonía entre los sectores públicos y privados.
Suiza, con dos ecuaciones para medir el tamaño y la masa de las moléculas (BBC NEWS, 2020).

3) El efecto browniano, trabajo en el que fue ayudado por su primera esposa Milena Maric, injustamente desconocida, brillante física y matemática, siendo en esta última disciplina en la que colaboró con Albert Einstein, pues recordaremos que él no era especialista y gracias a este trabajo, descubrió la estructura de partículas, cuya aportación estaba contra la opinión dominante que los explicaba como elementos continuos.

4) La teoría de la relatividad especial o la constante de la velocidad de la luz universalmente sobre 300 000 kilómetros por segundo, integrando tiempo y espacio, lo que después funcionó para explicar la curvatura del universo.

5) La equivalencia de la masa y la energía, un artículo publicado en noviembre de 1905 en el que "Einstein presentó la famosa fórmula $\mathrm{E}=\mathrm{mc}^{2}$ ".

6) La teoría general de la relatividad, aunque ésta fue publicada con amplitud en 1915 establece que el espacio-tiempo se puede entrelazar y deformar.

De acuerdo con Carlos Maldonado, la tercera revolución científica "Es la de la teoría o la ciencia de la información", al tiempo que recuerda que esta etapa, justamente, fue "La que se inició en 1949 con el famoso artículo de Shannon y Weaver entorno a la teoría matemática de la información" (Maldonado, 2020, 43) en este trabajo se considera que el mundo cuántico ha llegado una etapa superior y en él, las ciencias de la complejidad están totalmente inmersas, "Se encuentran implícitas entre la segunda y tercera revolución científica, las que tratan de la no-linealidad, la constitución y la emergencia de redes, la existencia de procesos de autoorganización, transiciones de fase de primer orden y de segundo orden, comparte con la teoría cuántica el rechazo del principio causalidad con un pensamiento relacional, en redes con términos como topografía, grafos, hipergrafos, percolación y otros" (Maldonado, 2020, p. 43).

\section{La teoría de redes sociales}

Así entramos en el universo cuántico en el que "Las redes sociales pueden definirse como un conjunto bien delimitado de actores-individuos, grupos, organizaciones, comunidades, sociedades globales, etcétera, vinculados unos a otros a través de una relación o un conjunto de relaciones sociales" (Lozares, 1996, p. 103-126).

Néstor Mena, otro investigador del tema, menciona que en la actualidad las redes sociales y sus factores de manejo de información son un lugar de elementos interrelacionados en los que "Las redes sociales han co- 
brado un papel muy importante en las teorías actuales al respecto de la creación y distribución de la información entre las personas que conforman una organización, ellas están cambiando la forma en que se gestiona la información personal e institucional. Las personas e instituciones interconectadas conforman un ecosistema, donde la actividad individual de gestión pasa ahora por la actividad colectiva en red". Por lo anterior es que "Para las instituciones, las habilidades individuales son paulatinamente substituidas por las habilidades para el trabajo en la red" (Mena Díaz, 2012, p. 29-37).

Hoy ha habido un crecimiento exponencial en las redes sociales con noticias falsas, oligopolios, conflictos globales de poder, impuestos y pagos a creadores de contenidos valiosos. Ante el inmenso poderío en las manos de un solo empresario, estamos de acuerdo con la fundada crítica del presidente de México. Más aún, es importante que de inmediato se estudie en las universidades, institutos, colegios, academias y el congreso sobre el tema para elaborar una legislación sin violar el derecho a la libertad de expresión, comunicación, prensa y también, el derecho al disentimiento para evitar las publicaciones anónimas o dolosas que dañen el prestigio y reputación de cualquier persona.

Como bien sabemos, cada red tiene nodos conformados por personas, grupos o instituciones, aristas o relaciones entre los mismos, el Análisis de Redes Sociales (ARS) permite calcular y determinar los actores que son centrales en la red; calcular y determinar los actores que se manifiestan como intermediarios, dominando o bloqueando la información de la red; calcular las transferencias de información entre los actores conectados, mapear las redes y comunidades en una institución a fin de visualizar como se transfiere la información en la organización" (Mena Díaz, 2012, p. 36). Por lo que el ARS "Es una metodología que busca, mediante la aplicación de la teoría de grafos, estudiar la estructura y predecir el comportamiento de los nodos que componen la red". Por ello, es extremadamente útil para conocer las interacciones de las actuales redes sociales.

Siendo un "Grafo una estructura matemática que permite moldear problemas de la vida cotidiana, a través de una representación gráfica formada por nodos y vértices que muestra a los actores y aristas que sirven para representar los lazos o las relaciones entre los actores" (Rochina, 2017, p. 28), mientras que la teoría de grafos "Es una rama de las matemáticas que estudia las propiedades de los grafos". Esta área de las matemáticas surgió gracias a un problema turístico que resolvió el brillante matemático Leonhard Euler en 1736 en un viaje a Königsberg, ante el problema de cruzar cada uno de sus seis puentes solamente una vez, y al fin demostró que era imposible (Álvarez Núñez, 2012, p. 34). ${ }^{2}$ Así, para estudiar a éstos en un campo como las redes sociales se emplean algoritmos para determinar a las comunidades de usuarios que comparten características comunes, relaciones e intereses "Siendo una comunidad, aquel subgrafo en el que los vértices deben estar más relacionados, entre sí, que con el resto de los otros vértices de la red". Para la identificación de las comunidades, se emplean los métodos jerárquicos y los métodos modulares centrados "En intentar encontrar la partición que maximice las modularidades".

El igraph es "Una colección de bibliotecas para crear, manipular gráficos y analizar redes, lanzado como estable en noviembre de 2020 por Gabor Csárdi y Thomas Nepusz, tal herramienta es capaz de manejar grandes redes de manera eficiente, es de código abierto". También debemos señalar que su desarrollo hoy nos permite recuperar información primaria o de entrada a un tema. Creada en 2001, hoy tiene 300 ediciones, 17 superan el millón de artículos, la escrita en inglés es la más grande con 6.3 millones, para México existen también en maya y náhuatl. En 2020 ingresaron mensualmente unos 1600 millones de dispositivos. Podemos ver este gran desarrollo, que ha transitado entre algoritmos para resolver problemas concretos dentro de un grupo de vértices en que confluyen intereses y una gran correlación para el manejo de las redes.

\section{Los gestores de bases de datos}

De acuerdo con el profesor de la Universidad de Granada e Ingeniero en Informática de Sistemas Rafael Marín, los sistemas de gestión de bases de datos (SGBD) - Data Base Management System (DBMS) son "Un sistema que permite la creación, gestión y administración de bases de datos, así como la elección y manejo de las estructuras necesarias para el almacenamiento y búsqueda de información del modo más eficiente posible, se pueden clasificar en relacionales y no relacionales" (Marín, 2019, p. 36), los anteriores sistemas, creados en 1970, son los más utilizados para la gestión de bases de datos, en especial Cassandra, empleada por los gigantes de las redes sociales y el streaming: Facebook, Twitter, Instagram, Spotify y Netflix por lo que podemos darnos cuenta de la demanda que tiene, debido a sus características sobresalientes.

Hoy vivimos en una semiósfera o espacio comunicativo global (Scolari, 2008, p. 51), existe el problema tipo Big Brother o Gran Hermano -aquel que todo lo ve- conforme la novela 1984 (Orwell, 2014, p. 143) del inglés George Orwell (1949), qué o quién por medio de los grandes datos o Big Data que enviamos través de nuestros televisiones o teléfonos inteligentes. Así, 
las empresas poseen una gran información sobre cada uno de nosotros, por lo que es indispensable legislar al respecto respetando los derechos humanos universales para que los ámbitos permanezcan tal cual y que la intimidad de lo privado no sea invadida por lo público.

Conforme con el postulado de Hans-Georg Gadamer, hablamos desde un contexto formado por cada una de nuestras propias historias para ejercer la hermenéutica o interpretación del texto (Gadamer, 2012, p. 333), lo que demostró en su larga vida plena de pensamiento y escritura (1900-2002), "En efecto, con su hermenéutica general, Gadamer nunca había querido afirmar que podemos entenderlo todo, sino, cuando mucho, que somos seres que procuran entender y fracasan muy a menudo en el intento" (Grondin, 2000, p. 433). No obstante, en cuanto a entendimiento, el maestro se mostraba cauto y aún precavido, pues deslindaba, sin duda, los límites del pensamiento humano y la velocidad de la máquina. Esto permite advertir la tecnociencia, que invierte el impulso ciencia-tecnología y, sin humanismo, dirige el avance material e ideológico con el consumismo de marca como ideología. Estamos en tiempos de grandes riesgos y de grandes cambios para defensa de la humanidad.

\section{Una ruta para México hacia el éxito}

Después de analizar el libro Estado Desarrollador. Casos exitosos y lecciones para México y Por qué fracasan los países (2019) a la conclusión que hemos llegado es que no hay receta para nuestro país por su historia, idiosincrasia, cultura, educación, inseguridad, etcétera, por el contrario, necesitamos comprender el momento en el que nos encontramos, en lo que el presidente Andrés Manuel López Obrador (2019, p. 172) ha Ilamado la Cuarta Transformación, siendo las anteriores: la Guerra de Independencia, la Reforma Juarista y la Revolución Mexicana, con una axiología que ordena "No mentir, no robar, no traicionar al pueblo, cero corrupción, una democracia participativa y un país con bienestar con una República fraterna" (2019, p. 183-186).

Ahora bien, nos enfrentamos a la pregunta ¿cómo la ciudadanía puede participar en el combate a la inseguridad? Conforme con la información que desde Estados Unidos nos ha llegado por la detención del exsecretario de seguridad pública Genaro García Luna, por corrupción, contubernio e impunidad, y la guerra emprendida por el entonces presidente de la República Felipe Calderón Hinojosa, con sus miles de muertos y desaparecidos, no fue más que para iproteger al Cartel de Sinaloa del "Chapo" Guzmán! (Espino, 2019, p. 1-6). Como respuesta del gobierno fue creada la Guardia Nacional, sin embargo, consideramos que esto no será suficiente sino que, por el contrario, es necesario armar a la ciudadanía, identificarla por sus antecedentes y actividad como un personaje ejemplar, capacitarla, controlarla perfectamente y registrar ante la Secretaría de la Defensa Nacional, por ejemplo, el rifle semiautomático LAR-8-X-1 de la fábrica Rock River Arms (Skyhorse, 2019, p. 200), con un control satelital del arma y del ciudadano. El presidente afirma que su ángel guardián es el pueblo de México, luego entonces necesita, en consecuencia, ángeles guardianes armados y supervisados cotidianamente por la Secretaría de la Defensa Nacional y la Marina Armada. Asimismo, debemos señalar que en el caso de Estados Unidos, con una población que rebasa a los de 331 millones de habitantes, se estima conforme a los datos de la cNN que en los hogares estadounidenses existen "El $48 \%$ de los 650 millones de armas en poder de los ciudadanos en el mundo", lo que representa que en cada casa de los estadounidenses existe cuando menos una pistola automática, revólver, rifle, subametralladora, en fin, armas de todo tipo, conforme lo permite su Constitución por la segunda enmienda a esa Carta Magna, realizada el 15 de diciembre de 1791 .

En el libro del presidente de la República, Andrés Manuel López Obrador - citado anteriormente, que lleva por título Hacia una economía moral- menciona que la corrupción es el primer problema de nuestro país y que ello se debe, en gran parte al fracaso del modelo económico neoliberal, lo que se confirma con los casos de Argentina, Chile y Perú. El Premio Nobel de Economía 2001, Joseph Stiglitz ha mencionado en sus diferentes libros que lo que el Fondo Monetario Internacional estimó como recomendado, no se reconoce hoy acertad, con una fórmula que indica que el $1 \%$ de la población tiene el equivalente de lo que posee el 99\% restante (2012, p. 187), en este nivel de desigualdad estamos de acuerdo con lo que el presidente López Obrador afirma, consideramos que necesitamos una República Moral con ciudadanos armados con una elevada ética y eficaz control, respetando siempre la división de poderes (Luhmann, 2010, p. 181) de aquí la necesidad de una adecuada regulación de las redes sociales, básica para la generación de ciudadanos.

Por lo que se refiere a la necesidad de "Cero corrupción" consideramos totalmente acertado este propósito, pues la famosa "mordida", que nos viene desde la Nueva España, implica un cambio cultural en el que se reconozca a los mejores, Enrique Peña Nieto expresidente de México, uno de los mandatarios más incultos que hemos tenido, en una ocasión afirmó que ella era una institución nacional, conforme a esto necesitamos instituciones sólidas no líquidas (Bauman, 2004, p.157) que encabecen el combate a la corrupción con la participa- 
ción de la ciudadanía organizada.

La austeridad republicana -inspirada en las palabras pronunciadas el 02 de julio de 1852 siendo gobernador de Oaxaca, Benito Juárez García- establece que el servidor público "Debe consagrarse asiduamente al trabajo, resignándose a vivir en la honrosa medianía que proporciona la retribución que la ley le haya señalado", representa lo opuesto de lo señalado en 1973 por un exgobernador del estado de México cuando expresó que "Un político pobre es un pobre político", por ello, López Obrador busca rescatar esta impronta moral de la Segunda Transformación, mantener la separación de lo empresarial y lo público, resaltado como "la consigna de nuestros liberales del siglo XIX de que "Al margen de la ley, nada y por encima de la ley, nadie" (2019, p. 79). Entendemos que en "Una democracia participativa" los ciudadanos honestos tienen derecho a tener armas para la defensa de sus casas, barrios, colonias, ciudades, estados y república, hoy la inseguridad no se ha logrado abatir en estados de la república cuya situación reconoce que unos están peores que otros, salvo Yucatán, en donde se ha involucrado a la sociedad, lo que permite suponer que sí podemos replicar lo que ocurre en tierras mayas al resto de los estados.

Concerniente al ingreso de las familias mexicanas percibimos que no solamente se debe buscar el crecimiento del PIB, sino que es totalmente válido para una mejor sociedad nacional y, de este modo, es posible ayudar a que los jóvenes y adultos se alejen de las adicciones, sin embargo, el problema es "Que se recibió una deuda pública de 10.5 billones de pesos, resultado de la irresponsabilidad y la corrupción de los gobiernos del régimen anterior, lo que obliga a destinar $749000 \mathrm{mi}-$ llones de pesos del presupuesto para pagar el servicio de la deuda. Sin embargo, con la fórmula de acabar con la corrupción y reducir el costo del gobierno se saldrá adelante" (2010, p. 134).

El actual régimen busca un país con bienestar, con fraternidad "Que es la manera más eficaz de para garantizar la gobernabilidad, el Estado de Derecho y la armonía social" (2010, p. 141), lo anterior, junto con el anhelo de garantizar educación pública hasta la Universidad, representa que tenemos un gobierno con rumbo hacia lo mejor, con un proyecto de nación alcanzable apoyándose en el paradigma emergente de la complejidad y la transdisciplinariedad, pues ante el problema complejo que es nuestro país exige, lógicamente, una respuesta compleja y transdiciplinaria.

\section{El exitoso caso de Finlandia}

La complejidad es una realidad en la era de la globaliza- ción que ha ido cambiando nuestra forma de ver la vida. En la sociedad actual, el consumismo se rige como fin, no como medio para satisfacer nuestras necesidades materiales y espirituales. Las amenazas sobre la humanidad avanzan en múltiples frentes, desde lo ecológico a la destrucción por las bombas y centrales atómicas, los retos están presentes día con día en los medios masivos de comunicación, en las redes sociales, pues cada vez se ahonda más la inquietud tanto de suficiencia alimenticia económica y de oportunidades, lo que va en contra de toda lógica humanística.

Stein (2018) considera que hay que resolver las problemáticas que afectan a todos los seres humanos hoy en día:

Desde una urbanización hasta la creación de empleos para millones de personas, los desafíos del mundo solo se resolverán si se utilizan enfoques que tengan en cuenta la Complejidad y el contexto local [...] El progreso de hoy se logra a costa de nuestros hijos. El cambio climático, la disminución masiva de la biodiversidad y el agotamiento de los recursos de la tierra y el agua dulce plantean graves amenazas para la humanidad. Se necesita un cambio inmediato y ambicioso en los patrones de producción y consumo (p. 3).

Hoy, viviendo en la segunda década del siglo XXI dentro de la complejidad de la globalización, la cultura del respeto de los derechos fundamentales es el nuevo paradigma y corriente iusjurídica que tiene como fundamento el respeto de la dignidad y los derechos fundamentales de toda la humanidad. Esta es una nueva cultura en construcción que busca la eficiencia del derecho y de la Constitución como forma en la justicia y vida universal, exponiendo o desnudando el imperio real de la ley del más fuerte propia del mercado, visible a nivel de lo estatal y lo social. Por ejemplo, dentro de los grandes problemas que padece México, aparte de la inseguridad, es la educación. Conforme con los resultados del estudio comparativo con Finlandia, verbigracia de éxito, pues el país ocupa siempre los primeros lugares dentro de los llamados primer mundo o desarrollados y de la Unión Europea. En el camino prueba seguido en la apuesta por la educación en este país incluyó a las mujeres, así al referirse a la segunda mitad del siglo pasado Eric Hobsbawm (2014, p. 313) menciona respecto de este país que en el ámbito universitario "Las mujeres hicieron, en número impresionante y cada vez mayor, de la enseñanza superior la puerta de entrada más visible a las profesiones de responsabilidad. Inmediatamente después de la Segunda Guerra Mundial, constituían entre el 15 al 30 por ciento de una avanzada en la lucha por la emancipación femenina, 
salvo Finlandia donde ya formaban casi el 43 por $100 "$.

Por otra parte, David Kirby (2010, p. 291) nos señala que el ingreso de Finlandia a la hoy Unión Europea ocurrió en 1995 así, luego de una votación, las diferencias vitales y generacionales se hicieron presentes "Las clases medias urbanas y los ciudadanos mayoritariamente por el sí; los grupos de más edad y la población rural, especialmente en las regiones del este y del norte votaron por el no". Sin embargo, Finlandia ha tenido dificultades relacionados con la crisis económica que padeció debido a la globalización: "El público desconfiaba profundamente de los políticos y en la inmediata consecuencia de los problemas bancarios, la percepción popular fue que los políticos habían rescatado a los bancos a costa del público".

Ante el advenimiento de la mecanización del campo "Miles de hijas de granjeros eligieron dejar la tierra antes que convertirse en la esposa de un granjero" (2010, p. 306), es evidente que con las universidades abiertas a la población femenina, muchas jóvenes se integraron al sistema de educación superior, con el efecto de que Finlandia tendría una fuerza laboral altamente capacitada en la medicina, economía, derecho, cibernética, humanidades y un largo etcétera. Como mencionó en una entrevista periodística un dirigente fines cuando le preguntaron cuál era el secreto del desarrollo de su país, él simplemente repitió: "Educación, educación y educación".

Consideramos que desde la disciplina del conocimiento estético, la educación (uNESCO, 2015, p. 61) se amplía como no puede desarrollarse desde la técnica ni la ciencia, por el contrario, el conocimiento estético profesa una naturaleza diferente. Destacamos desde un principio su distinta naturaleza de conformidad con Immanuel Kant es "Aquel que no se expresa con conceptos", lo anterior en virtud de que se relaciona con nuestras emociones, sentimientos e instintos $y$, tiene como supremo juez y valor máximo a nuestro gusto o repulsión, así, la afirmación de cada persona sobre lo bello es una afirmación universal, concreta, que tiene valía insuperable y definitiva.

Partiendo del postulado de que el ser humano naturalmente tiende hacia el conocimiento y hacia la belleza (Aristóteles, 2015, p. 64), por nuestra parte consideramos que el derecho es arte cuando cumple con las cualidades estéticas de proporción, armonía y esplendor. La primera la contemplamos desde la aristotélica justicia distributiva, que es aquella que atiende a la manera conforme a la cual se reparten los bienes, riquezas y oportunidades de una nación; la segunda es la que permite la paz social, gracias a una cultura de respeto al derecho propio y de los demás, por último, la empleamos como reconocimiento de que brilla el derecho, cuando se cumple de la mejor manera su búsqueda eterna de justicia. Para llegar a esta conclusión nos hemos apoyado principalmente en los estudios y reflexiones estéticas antes desarrolladas. Debemos reconocer que los pensadores nos llevaron de la mano facilitándonos la labor, lo que agradecemos, junto con las obras de Francisco Larroyo (1979, p. 25), 3 Umberto Eco y J. F. Rafols.

Empezamos por el pensamiento de Pitágoras, quien sostuvo que el cosmos se puede comprender y explicar por medio de los números y que el arte debe guardar proporción y armonía -estos valores dominarán a la estética griega por siglos- y que la belleza máxima se expresa a través de las formas geométricas.

Asimismo, concuerda en la misma línea de pensamiento la afirmación de Sócrates cuando desde el idealismo considera en El Banquete o Simposio que una vida contemplando la belleza es una vida que vale la pena ser vivida; de igual modo la sentencia de Estagirita, quien en el capítulo quinto de su Arte Poética sostiene que el arte debe seguir reglas (Aristóteles, 2007, p. 67), mismas que retoma de Pitágoras, señalando que tales directrices son la proporción y la armonía. Kant (17241804) en sus obras Observaciones sobre el sentimiento de lo bello y lo sublime, Crítica de la razón pura y Crítica del juicio sostiene que la estética es lo universal sin concepto, lo que significa que por atender al sentimiento no puede ser ciencia, pues no interviene aquí la razón ni el concepto. Dicha afirmación: "A cualquiera, una obra artística" basta para convertirse, ante todo el mundo, como una máxima universal, ante la cual no tiene valor otra máxima que lo niegue; en consecuencia lógica, en el arte brilla la libertad máxima ligada a nuestros sentimientos.

En 1881 publica su Crítica de la razón pura en la que aborda a la estética (Kant, 2008, p. 66), con el precedente de que, después de terminar en junio de 1787 su Crítica de la razón práctica, en donde estudia, entre otras ciencias, al derecho, le comunica a Schütz que trabaja en lo que será publicado en el año de 1790 como Crítica del juicio, que culmina sus reflexiones sobre el arte (Kant, 2004, p. 164), mismas que empezó en 1864 con Observaciones sobre el sentimiento de lo bello y lo sublime. Por lo anterior, podemos darnos cuenta y reconocer que el racionalismo cartesiano no logró opa-

3 Afirma que la estética es el estudio de los problemas relativos al arte y la belleza, mientras que ésta atiende al conocimiento sensible, la lógica es la ciencia del conocimiento abstracto. Disentimos, pues consideramos que la lógica no es ciencia sino disciplina, por no tener objeto propio de estudio. 
car la clara reflexión sobre el arte en Kant, puesto que el filósofo invirtió un cuarto de siglo en reflexiones y postulados al respecto. Así, Ernst Cassirer, neokantiano editor de sus obras completas, afirma respecto de la década que va de los sesenta a los setenta años de su vida que "Las obras de esta época de la vida de Kant revelan la fuerza creadora de la juventud, unida a la madurez y a la perfección de la vejez" (Cassirer, 2003, p. 318).

Por su parte, Schiller representa la armonía universal por el camino de la libertad y la tolerancia. Francisco Larroyo sostiene que el arte existe desde que el hombre es hombre (Larroyo, 1979, p. 19), sin embargo, debemos matizar esta afirmación, pues es un producto cultural de la humanidad que ha pasado por diversas épocas, sin que estemos de acuerdo con su afirmación de que "La estética es una de las ciencias fundamentales de la filosofía", pues concordamos con Kant en su criterio de que es lo universal sin concepto, por lo tanto, no puede ser, por consecuencia, ciencia, pues está ligada al sentimiento y no a la razón, en efecto, no puede ser una construcción teorética, porque cada una de ellas se construye con conceptos; siendo el concepto un producto lógico socrático que atrapa la esencia de los seres, entes o procesos por medio de la razón, lo que difiere con el arte, al conectar el objeto bello o estético con el sentimiento, emoción o instinto, mas no con el razonamiento.

Aparte de la antigua posición de que el arte imita a la naturaleza nos encontramos con la reciente, de que lo estético es realización humana (Marchán Fiz, 2000, p. 248), así Arturo Chavolla de la Universidad de Guadalajara lo expresa en una ponencia (Chavolla, 2015, p. 1-17) que invita a la reflexión.

Además, hoy existe una razón que impulsa al arte como parte de la cultura, pues con tantos ejércitos armados con proyectiles nucleares y centrales productoras de electricidad a partir de la fisión del átomo, de acuerdo con lo postulado por Sigmund Freud en su pensamiento "Las actitudes psíquicas que nos han sido impuestas por el proceso de la cultura son negadas por la guerra en la más violenta forma y por eso nos alzamos contra la guerra [...] y pareciera que el rebajamiento estético implícito en la guerra contribuye a nuestra rebelión contra ella en grado no menor que sus crueldades" (Freud, 1973, p. 3215). Ello lleva a apreciar las enseñanzas del marxismo cuando se afirma que la política influye determinantemente en el arte (Morawski, 1977, p. 431).

Por nuestra parte, concluimos que el derecho es técnica como se muestra en los procesos civiles o penales; es ciencia, pues parte de conceptos jurídicos funda- mentales, junto con el empleo de lógicas para razonar, métodos para realizar sus labores e incluso llega a la epistemología jurídica por medio de rompimientos y claves epistémicas; y es arte, porque cumple con las condiciones que, desde el inicio los pitagóricos y posteriormente los demás filósofos -Baumgarten, Lessing, Kant, Hegel, Schiller, Taine- establecieron como directrices de la belleza: proporción, armonía, esplendor y equilibrio.

Asimismo, el conocimiento estético nos ayuda en el ejercicio de nuestra profesión de profesores y abogados de acuerdo con los quehaceres jurídicos en la postulancia, judicatura, docencia, investigación o consultoría, tal cual menciona Manuel Atienza (2003, p. 255 y ss.), al enriquecernos con este tipo cognitivo o epistémico que muy pocos hemos cultivado, cuyos principios podemos seguir en la búsqueda de la comunicación en las organizaciones.

La proporción se identifica con la justicia distributiva señalada por Aristóteles como la manera en que la sociedad reparte bienes y oportunidades; la armonía social se vislumbra disciplina como fin del derecho, para poder vivir en paz; el esplendor debe estar siempre presente, así decimos que "Brilló la justicia" cuando consideramos que una sentencia la honró y el equilibrio como forma de vida, permite que toda sociedad se desarrolle sin los excesos de quien todo lo tiene de sobra y de aquellos que carecen de lo más elemental; aquí recordamos al poeta Salvador Díaz Mirón (1853-1928) quien afirmó en su poema Asonancias: "Nadie tendrá derecho a lo superfluo, mientras alguien carezca de lo estricto".

\section{Nuevas reflexiones en el marco de las or- ganizaciones inteligentes y la complejidad}

Si seguimos la etimología de las palabras, que tanta información nos aporta, hallamos que lo complejo significa "Lo que está tejido junto". En igual forma, continuando con el término actual "Lo global es el conjunto que contiene partes ligadas de manera inter retroactivas y organizacional" podemos mencionar la globalización como dominio mundial del capitalismo financiero que controla cognitiva y poiéticamente con la tecnociencia, en lo económico por medio de organismos internacionales y culturalmente por medio de la industria de la televisión y el cine.

La complejidad como reto que enfrenta a la ciencia clásica newtoniana-cartesiana nos obliga a abrir nuestro pensamiento ante una nueva visión de la realidad, lo que implica que necesitemos recurrir a la transdisciplinariedad, para que articule los diferentes conocimientos disciplinarios, desde el referente básico del bucle mo- 
raniano, de modo que podamos construir una malla multidimensional que nos permita atrapar a todos los entes para alcanzar a llegar al pensamiento complejo totalizador, holístico e integral.

El paradigma emergente de la complejidad nos invita a reflexionar sobre él, comenzaremos señalando que el referente básico en la complejidad es el bucle (Morin, 1990 , p. 37) mientras que el concepto socrático es la unidad básica de la ciencia y el metaconcepto hegeliano-carrolliano es la unidad básica de lo epistémico; la anterior afirmación nos obliga a desarrollar metafóricamente al bucle y, sostenemos, que es como las olas del mar con el principio recursivo, en el que todo efecto produce una causa y cada causa, de nueva cuenta es efecto. Lo poiético con su efecto autoconstructivo se aplica aquí, por ello, podemos identificar al bucle como el ser lógico transdiciplinario que dinámicamente produce lo complejo. Evidentemente, lo transdisciplinario conlleva bucles y éstos, recursivamente producen lo transdisciplinario en una renovadora e incesante retroalimentación.

Lo transdisciplinario (Nicolescu, 1996, p. 10) implica el cruce de las disciplinas tal como atraviesa una flecha su objetivo. También conlleva una translógica, la cual explicamos como aquella que maneja las diferentes lógicas disciplinarias integrando consecuentemente un tejido, en el que cada ciencia constituye un hilo que nos permite construir un lienzo con el que podemos explicar una realidad determinada. Así, se crea una translógica, que penetra y se mueve como una flecha en el tiempo disciplinario, rompiéndolo para crear una nueva dinámica que permita, desde el pensamiento complejo, comprender lo sujeto a comprensión y explicación a partir de un segundo orden.

Si realmente deseamos comprender desde el pensamiento complejo al ser humano, también necesitamos aceptar que es un ser racional, emocional, pasional, espiritual, instintivo y cultural, esto último implica lo histórico y lo lingüístico, así como todas aquellas aportaciones que la humanidad ha hecho a lo largo de su historia. En este sentido, el legado de Freud (1978, p. 237) es invaluable, al igual que el de Heidegger (2013, p. 113) y Ludwig Wittgenstein (2012, p. 86), podemos afirmar que, si la muerte es un sueño eterno, la vida es un despertar de solamente $x$ años.

Lo complejo es cuántico, no es digital con su lógica binaria de 0 o 1 , sino que aquí el 0 y el 1 se hermanan y esto nos lleva a lo infinito cuando se recorre la distancia del 0 al 1, luego, así apreciamos el cambio de la lógica disciplinaria a transdisciplinaria. Gracias a pensadores como Edgar Morin e Ilya Prigogine (1999, p. 56) la humani- dad ha podido desarrollarse, mientras que las ciencias llegan hasta donde el ser humano ha logrado avanzar, lo transdisciplinario, como pensamiento complejo, genera un nuevo conocimiento. En suma, estamos ante un nuevo diálogo de todas las ciencias, técnicas, artes y tecnologías que la Humanidad ha desarrollado. Esto nos permite situarnos en la frontera de los conocimientos y nos lleva a un saber desde la complejidad.

Mientras que en la epistemología de primer orden estamos en el campo del conocimiento del conocimiento (González, 2019, p. 56), en la epistemología de segundo orden reside ante lo sapiencial, entonces, congruentemente, debemos manejar el saber del saber, aquí nos ayuda mucho Heidegger cuando menciona que la nada nadea, lo que es muy fácil de demostrar en nuestros alimentos envasados al alto vacío, que implican que la nada del oxígeno y otros gases, al eliminarse por tal procedimiento industrial, permiten evidentemente que la nada, nadee. En el caso del 0 también se presenta la nada, permite que una unidad con el 0 a la derecha eleve al número 10 , la cantidad de entes que expresamos con ese 0 , que no ejercería su función si estuviera a la izquierda, luego entonces, para que el cero nadee, es necesario que se coloque a la derecha.

El originario cero en maya-oriental es una negación-afirmación de lo abstracto-numérico que permite romper la barrera de la suma para transitar a otro orden lógico, infinito en el que en el número 10 o 20 de la nada, nadea con su potencia originaria. La lógica del cero nos permite pasar a un segundo orden, generado por la generatividad de lo originario: es la nada que nadea potenciando a una unidad para transformarla en 10 unidades, así el 1 se convierte en 10 manzanas, que no es una simple suma sino es otra lógica que, dinámicamente en el 10, el 20 o el 30, se manifiesta gracias al poder originario del cero o la nada, que nadea en todo su esplendor (Heidegger, 2013, p. 98).

Lo sapiencial del segundo orden de la epistemología de esta calidad implica superar la epistemología del primer orden, la cual nos permite manejar los conocimientos disciplinarios de cada ciencia que cada uno desee desarrollar, mientras que en el segundo orden ya se exige superar lo anterior, tal como lo expresó Hegel, si el metaconcepto es la unidad básica de la epistemología del primer orden entonces "La pena es la negación de la negación del derecho" (1997, p. 387), o siguiendo a Lewis Carroll cuando declaró que "No se pueden ni perder aquellos que no saben a dónde quieren ir" (2010, p. 66), o también en su aseveración lapidaria: "Cualquier camino es válido para quienes carecen de la voluntad de dirigirse hacia un destino determinado" (p. 72). Por lo que respecta a la inseguridad que hoy manifiesta 
nuestro país, consideramos que las redes sociales nos pueden servir como organizaciones para combatirla con la participación ciudadana armada y controlada por la Guardia Nacional, el ejército y la Marina. Después de mucho reflexionar, no encontramos otra mejor solución que contribuya a combatir este mal.

Por su parte, en términos de educación, las redes sociales permiten la comunicación digital interactiva que facilita que el proceso de enseñanza-aprendizaje se efectúe dentro de una cibercultura en la cual todos aprendemos de todos y, no como antes, de profesor al alumno, bajo la tiránica consigna de magister dixit ergo, ita est, (lo que dice el maestro luego es verdad), por el contrario con el internet podemos consultar cualquier dato desde la red superficial como Wikipedia hasta la red de revistas indexadas de reconocido prestigio que nos garantizan situarnos en las fronteras de la ciencia y el arte.

Hoy estamos construyendo una cibercultura, pues en términos de la teoría o teorías de la comunicación digital interactiva, somos la primera generación que ya no depende de la edad, sino del estudio que cada uno realice del conocimiento ciber comunicacional con nuevos conceptos, términos, dentro de una semiósfera o, tal vez mejor, como afirma Pierre Lévy, cosmopedia 4 que abarca redes de redes por medio de las hipermediaciones, en las que, conforme nuestro autor, "Lo virtual no es, en modo alguno, lo opuesto a lo real, sino una forma de ser, fecunda y potente que favorece los procesos de creación, abre horizontes, cava pozos llenos de sentido bajo la superficialidad de la presencia física inmediata" (1999, p. 8) y las hipermediaciones son según Scolari son "Procesos de intercambio, producción y consumo simbólico que se desarrollan en un entorno caracterizado por una gran cantidad de sujetos, medios y lenguajes interconectados tecnológicamente de manera reticular entre sí" (2008, p. 113-114).

Por consiguiente, podemos afirmar que organizar redes sociales para fomentar el conocimiento, la educación y la mejor relación entre las comunidades científicas, académicas y cualquier persona interesada en los nuevos conocimientos de la cibercultura es de lo más pertinente, pues nos permite aprovechar las nuevas tecnologías

$4 \quad$ Término creado por Pierre Lévy (1956), alumno de los intelectuales Michel Serres (1930-2019) y Cornelius Castoriadis (1922-1997). Es considerado como el "Filósofo del ciberespacio". El Consejo de Europa le pidió un estudio sobre las repercusiones de las tecnologías digitales de comunicación e información (TICS) en 1997 lo que resultó la publicación de un libro titulado Cibercultura. La cultura de la sociedad digital, México: Universidad Autónoma Metropolitana, Unidad Azcapotzalco, Editorial Anthropos. de información y comunicación que, hoy por hoy, son nuestros nuevos instrumentos para movernos con inteligencia colectiva en los cuatro espacios antropológicos históricos de Lévy siendo las anteriores: la tierra con el homo sapiens como actor recolector y cazador de una tribu, en la que el más viejo encarna al conocimiento acumulado por la experiencia; en cuanto al territorio. Desde el neolítico, la agricultura permite al ser humano asentarse, termina su dependencia de la caza y la pesca, la tierra es la base de la riqueza, surge el libro y, el más viejo ya no es el más sabio, sino el más estudioso, las ciudades se desarrollan, surgen las polis, los imperios, los Estados-Nación; las mercancías o bienes a partir del capitalismo primero, de tipo comercial, con ejemplos como Venecia, Florencia y otras a la cabeza; y finalmente, con la Revolución Industrial del siglo xVIII empieza la última era que se prolonga hasta el día de hoy con la sociedad de la información, del conocimiento.

Así nos dirigimos velozmente hacia lo virtual, con la utilización de la relación computadora-usuario, redes, hipermediaciones, comunicaciones digitales interactivas, sociedad digital, robótica y demás. Todo un universo por construir en la historia de la humanidad con promesas, riesgos y oportunidades.

\section{Bibliografía}

Aguado, Juan Miguel (2004). Introducción a las teorías de la información y la comunicación. España: Universidad de Murcia.

Álvarez Núñez, Marcelino Felipe y Jonathan Alejandro Parra Muñoz (2013). Teoría de grafos. Chile: Universidad del Bio-Bio.

Aristóteles (2015). Metafísica. Francia: fv Éditions. (2007). Arte retórica. [José Goya y Francisco de P. Samaranch, Trad.]. México: Porrúa.

Atienza, Manuel (2003). Introducción al Derecho. México: Fontamara.

BBC NEWs (2020). "Einstein el año milagroso en que escribió 5 estudios científicos que revolucionaron la física". https://www. bbc.com/mundo/noticias-52596330\# : :text=Mientras $\% 20$ trabajaba\%20 evaluando $\% 20$ solicitudes $\% 20$ de, milagroso\%22)\%20del\%20f\%C3\%ADsico\%20alem\%C3\%A1n.

Bruhn Jensen, Klaus (2014). La comunicación y los medios. Una metodología de investigación cualitativa y cuantitativa. [Mariano Sánchez-Ventura, Trad.]. México: Fondo de Cultura Económica, México.

Cassirer, Ernst (2003). Kant, vida y doctrina. México: Fondo de Cultura Económica.

Chavolla, Arturo (2015). "Filosofía del cine". Sincronía.

Freud, Sigmund (1973). "El porqué de la guerra". Obras completas. Madrid: Editorial Biblioteca Nueva.

Gadamer, Hans-Georg (2012). Verdad y método. [Ana Agud Apari- 
cio y Rafael de Agapito, Trad.]. España: Ediciones Sígueme.

(2000). Una biografía. [Ángela Ackermann Pilári, Roberto Bernet y Eva Martín-Marca, Trad.]. Barcelona: Herder.

Kant, Emmanuel (2008). Crítica de la razón pura. México: Editorial Porrúa.

(2004). Observaciones sobre el sentimiento de lo bello y lo sublime. México: Editorial Porrúa.

Larroyo, Francisco (1979). Sistema de la estética. México: Editorial Porrúa.

Lévy, Pierre (1999). ¿Qué es lo virtual? (Diego Levis, Trad.). Barcelona: Paidós.

(2007). Cibercultura. La cultura en la sociedad digital, México: Anthropos-Universidad Autónoma Metropolitana.

Lozares, Carlos. "La teoría de las redes sociales". Papers 48 (1996).

Maldonado, Carlos Eduardo (2021). Estética y complejidad. Elementos para un estado crítico del arte. Bogotá: Editorial Corporación Creación. Arte y Ciencia. Bogotá.

(2020) Teoría de la información y complejidad. Bogotá: Universidad El Bosque, Bogotá.

Marchán Fiz, Simón (2000). La estética en la cultura moderna. Madrid: Alianza Editorial.

Mena Díaz, Néstor. "Redes sociales y gestión de la información: un enfoque desde la teoría de grafos". Ciencias de la Informa- ción 43 (2012)

Morawski, Stefan (1977). Fundamento de estética. Barcelona: Península.

Rochina, Paola (2017)."El análisis de redes sociales mediante la teoría de grafos". Revista Digital INESEM.

Schwab, Klaus (2017). La cuarta revolución industrial. México: Debate.

Scolari, Carlos, (2008). Hipermediaciones. Elementos para una teoría de la comunicación interactiva, Barcelona: Gedisa.

Stein, Achim (2018). "Prólogo: el estado del desarrollo humano mundial 2018." Programa de las Naciones Unidas para el desarrollo humano. Actualización estadística de 2018. Nueva York: PNUD.

UNESCO (2015). Replantear la educación. ¿Hacia un bien común mundial? Francia: UNESCO. 